\title{
Left Internal Mammary Artery Dissection during Percutaneous Coronary Intervention in Hypertensive Patients
}

\author{
Marco Vatrano', Roberto Ceravolo', Giuseppe Dattilo², Vincenzo Antonio Ciconte ${ }^{1}$ and Egidio Imbalzano $^{2 \star}$
}

${ }^{1}$ UTIC and Cardiology, Hospital "Pugliese-Ciaccio" of Catanzaro, Italy

${ }^{2}$ Department of Clinical and Experimental Medicine, University of Messina, Italy

\begin{abstract}
Left Internal Mammary Artery (LIMA) dissection is a potential catastrophic complication of percutaneous coronary intervention $(\mathrm{PCl})$ rarely observed in hypertensive patients. There are very few reports but the paucity of data regarding the incidence capture the imagination more than other coronary dissections. Additionally, for the management of this iatrogenic complication there are no evidence-based guidelines to assist the operator. We present a case of two diagnostic catheter-induced dissections of LIMA successfully resolved with long multiple stenting, and review the existing literature. In our opinion, these case reports describe a very rare condition in hypertensive patients with some practical tips on how to avoid them, whereas there are very few published data. Moreover, we have shown that stenting has been used to solve a potentially deadly procedural complication, in a basal extremely serious clinical situation.
\end{abstract}

Keywords: Internal mammary artery dissection; Diagnostic angiography; Hypertension; Acute coronary syndrome

\section{Case Report 1}

A hypertensive and obese 58-year-old male with acute coronary syndrome without ST elevation (nSTEMI), was admitted to our department. The patient's past medical history also included previous myocardial infarction in his 53 years, treated with primary percutaneous coronary intervention and stenting of Left Anterior Descending (LAD) coronary and, in the following years, he underwent a LIMA bypass grafting due to restenosis of previous stenting unsuitable for new percutaneous intervention. Native coronary angiography was performed by left radial access with 5Fr JL 3.5 and JR 3.5 diagnostic catheter (both Medtronic). The LIMA was easily cannulated with the same JR 3.5 diagnostic catheter. A manifold was utilized for hand injections of contrast. The first injection showed a sub-occlusive lesion of distal segment of the graft (Figure 1A). Before even proceeding with LIMA angioplasty, the patient developed severe chest pain and ST segment modification. Angiography was immediately repeated and it revealed total occlusion of proximal segment of the LIMA with TIMI (thrombosis in myocardial infarction) 0 flow (Figure 1B). Then, an Intermediate guidewire (Asahi Intecc, Japan) was passed beyond the occlusion to the LAD artery and a series of balloon inflations were carried out. With the next injection of contrast, a large spiral dissection was seen extending down the LIMA with TIMI grade I flow (Figure 1C). A decision not to stent the entire length of the LIMA was made since the dissection ended well before the baseline stenosis. The LIMA was treated with three overlapping drug-eluting stents $(3.0 \times 26 \mathrm{~mm}$, $3.0 \times 30 \mathrm{~mm}, 3.0 \times 30 \mathrm{~mm}$ ) from the distal to the proximal portion of the graft. Finally, one last drug-eluting stent $(2.5 \times 15 \mathrm{~mm})$ was placed on the basal stenosis and the expansion of all the stents was optimized with a series of non-compliant balloon inflations with final TIMI 3 flow (Figure 1D). The patient had an uneventful post-procedural course and he has done well to date without any further complications.

\section{Case Report 2}

A hypertensive 67-year-old female with a history of coronary artery disease and coronary artery bypass grafting, was referred to our department for diagnostic angiography after a positive cardiac stress test. Native coronary angiography was performed by right femoral

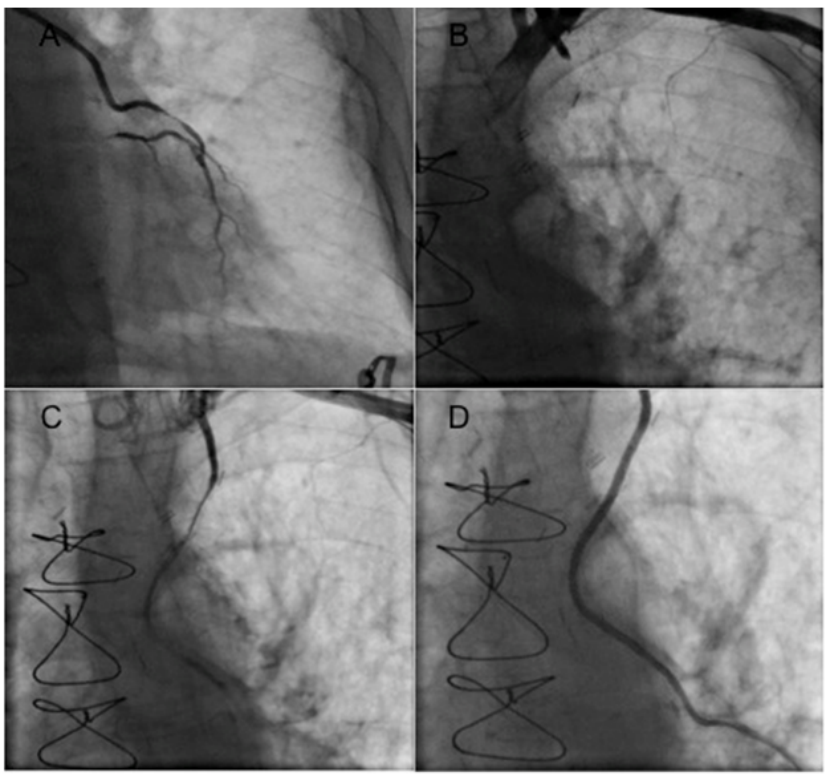

Figure 1: A sub-occlusive lesion of the LIMA graft is seen with no evidence of dissection (A); Abrupt occlusion of the LIMA graft (B); A linear dissection is now present in the LIMA graft after balloon (C); There is no evidence of residual dissection in angiogram following stents deployment in the LIMA graft (D).

*Corresponding author: Egidio Imbalzano, Unità Operativa Complessa di Medicina Interna,Azienda Ospedaliera Universitaria "Policlinico G. Martino" Via Consolare Valeria, 198125 Messina, Italy, Tel: +393392894665; E-mail: eimbalzano@unime.it

Received January 23, 2014; Accepted February 18, 2014; Published February 25,2014

Citation: Vatrano M, Ceravolo R, Dattilo G, Ciconte VA, Imbalzano E (2014) Left Internal Mammary Artery Dissection during Percutaneous Coronary Intervention in Hypertensive Patients. J Clin Exp Cardiolog 5: 287. doi:10.4172/21559880.1000287

Copyright: (c) 2014 Vatrano M, et al. This is an open-access article distributed under the terms of the Creative Commons Attribution License, which permits unrestricted use, distribution, and reproduction in any medium, provided the original author and source are credited. 
Citation: Vatrano M, Ceravolo R, Dattilo G, Ciconte VA, Imbalzano E (2014) Left Internal Mammary Artery Dissection during Percutaneous Coronary Intervention in Hypertensive Patients. J Clin Exp Cardiolog 5: 287. doi:10.4172/2155-9880.1000287

access with 6Fr JL 3.5 and JR 3.5 diagnostic catheter (both Medtronic). The LIMA was easily cannulated with the same JR 3.5 diagnostic catheter. A manifold was utilized for hand injections of contrast. The first and the second injection showed a patent graft (Figure 2A). The third injection of contrast showed a large spiral dissection with TIMI grade I flow to the LAD (Figure 2B). The patient developed severe chest pain and ST segment elevation. An intra-aortic balloon pump (CS100 Datascope, MaquetGentinge Group) was inserted by the left femoral artery. A decision was made to stent the entire length of the LIMA with three overlapped drug-eluting stents $(2.25 \times 22 \mathrm{~mm}, 2.5 \times 22 \mathrm{~mm}, 2.5$ $\times 30 \mathrm{~mm}$ ) from the distal to the proximal portion of the graft. Finally, the expansion of all the stents was optimized with a series of noncompliant balloon inflations with final TIMI 3 flow (Figure 2C). Also this patient had an uneventful post-procedural course and she has done well to date without any further complications.

\section{Discussion}

The LIMA graft has shown superior patency rates compared to the saphenous vein graft (SVG), as reported by copious medical literature [1]. Given these results, it has become the conduit of choice for bypass of the LAD artery, with a $>98 \%$ early patency rate and an $80-93 \%$ late patency rate. Furthermore, given the long life of the LIMA graft, some operators have described a growing number of diagnostic angiograms post bypass over the years, and those requiring LIMA percutaneous intervention, although rare, have increased in frequency $[2,3]$. However, diagnostic accuracy of multidetector Computed Tomography Angiography (CTA) has improved considerably, and the development of non-invasive diagnostic modality could reduce the necessity of diagnostic catheterization after CABG. The LIMA can be a challenging vessel to catheterize due to its acute angle of origin from the left sub-clavian artery. For graft engagement, an IMA catheter is preferred over JR as it is more co-axial and catheter manipulation should be very done very carefully to avoid complications. Another risk factor of LIMA dissection could be the catheter size. Recently, the size of the diagnostic catheter has been down-sizing progressively. Catheter-induced dissection of the LIMA was first described in 1985 and there is little published data regarding incidence in hypertensive patients of this iatrogenic complication [4-7]. More frequently,

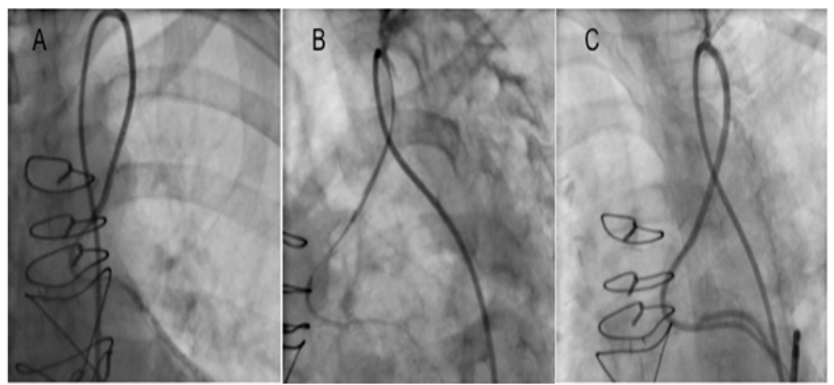

Figure 2: A patent LIMA graft is seen with no evidence of dissection (A); $A$ linear dissection is now present in the LIMA graft $(B)$; There is no evidence of residual dissection in angiograms following stents deployment in the LIMA graft (C).

Citation: Vatrano M, Ceravolo R, Dattilo G, Ciconte VA, Imbalzano E (2014) Left Internal Mammary Artery Dissection during Percutaneous Coronary Intervention in Hypertensive Patients. J Clin Exp Cardiolog 5: 287. doi:10.4172/2155-9880.1000287 authors described spontaneous dissection of the graft. Furthermore, they suggested that multiple stenting is the best treatment for LIMA dissection [8-10]. However, long stenting is still controversial. As the LIMA dissection is catheter-induced, and is thus initiated from ostium of LIMA, if the hematoma does not compress the true lumen, and does not compromise the flow, the length of bailout stent might be able to be minimized only to cover the ostium [11]. Our two cases, therefore, add further important information regarding a complication which may be underreported due to reluctance to expose iatrogenic events. In our department, we had an incidence of iatrogenic dissection of the LIMA of about $0.01 \%$ and, given our experience, we would suggest avoiding, when possible, selective engagement of the graft, especially with an unfit catheter. We prefer to use a 5Fr IMA catheter. Furthermore, when treating a LIMA dissection, emergency bailout stenting could be the only key to obtaining a rapid coronary reperfusion and hopefully possible success.

\section{References}

1. Barner HB, Standeven JW, Reese J (1985) Twelve-year experience with internal mammary artery for coronary artery bypass. J ThoracCardiovascSurg 90: 668-675.

2. Kuntz RE, Baim DS (1990) Internal mammary angiography: a review of technical issues and newer methods. CathetCardiovascDiagn 20: 10-16.

3. Zimarino M, Pichard AD, De Caterina R, Calafiore AM (2001) Percutaneous interventions on arterial conduits. J Invasive Cardiol 13: 114-120.

4. Farooqi S, Jain AC, O’Keefe M (1985) Catheter-induced left internal mammary artery bypass graft dissection. CathetCardiovascDiagn 11: 597-601.

5. Freeman SP, Liston MJ, Lips DL, Vacek JL (2004) Catheter-induced left internal mammary artery dissection: a report of two cases and review of the literature. J IntervCardiol 17: 117-121.

6. Neugebauer P, Jerabek P, Kala P, Bocek O, Poloczek M, et al. (2010) Guiding Catheter-Induced Dissection with the Closure of the Last Patent Bypass Graft-A Case Report. J Kardiol 17.

7. Imbalzano E, Trapani G, Creazzo M, Lizio G, Saitta A (2013) Coronary artery disease in radiotherapy. Int J Cardiol 168: e125-126.

8. Gruberg L, Dangas G, Mehran R, Hong MK, Waksman R, et al. (2000) Percutaneous revascularization of the internal mammary artery graft: Shortand long-term outcomes. J Am CollCardiol 35: 944-948.

9. Sardo MA, Mandraffino G, Campo S, Saitta C, Bitto A, et al. (2009) Biglycan expression in hypertensive subjects with normal or increased carotid intimamedia wall thickness. ClinChimActa 406: 89-93.

10. Moon CH, Nanavati VI (1999) Multi-stent approach in the treatment of acute dissection of the left internal mammary artery. J Invasive Cardiol 11: 248-250.

11. Zago AC, Matte BS (2013) Friable but treatable: coronary artery dissections in Ehlers-Danlos syndrome. Catheter CardiovascInterv 81: 75-79. 